\title{
Ship to Ship Transfer of Cargo Operations: Risk Assessment Applying a Fuzzy Inference System
}

\author{
Dimitrios I. Stavrou, Nikolaos P. Ventikos \\ National Technical University of Athens, School of Naval Architecture and Marine Engineering, \\ Laboratory for Maritime Transport (Maritime Risk Group) \\ 9 Iroon Polytechniou str. Zografou 15773, Greece, \\ E-mail: (D. I. Stavrou)dstaurou@gmail.com (N.P.Ventikos)_niven@deslab.ntua.gr
}

Received 14 August 2014

Accepted 23 October 2014

\begin{abstract}
Although the safety records for Ship to Ship (STS) transfer operations reflect to safe procedures, nevertheless it remains a complex operation that needs special consideration due to the adverse consequences of a potential accident. The aim of this paper is to apply fuzzy inference system as a novel approach for risk assessment for STS transfer operations. The advantages of the fuzzy approach are highlighted through the application of the Mamdani's method for hypothetical accident scenarios.
\end{abstract}

Keywords: Ship to Ship transfer, fuzzy inference system, risk assessment.

\section{Introduction}

The Ship to Ship (STS) transfer of cargo is a procedure that was initially used on the decade of 1960s due to the increased draft dimension that limited the access of large ships (VLCCs and ULCCs) at specific oil terminals through shallow rivers in the Gulf of Mexico ${ }^{1}$. Although the initial use of such procedures was for transferring oil, however the contemporary STS operations have been extended to the transfer of cargoes other than oil, such as liquefied gases (LPG, LNG) or even for dry cargoes such as ore; nevertheless, the dry bulk STS operations are mostly conducted in the Middle and Far East where iron ore is transshipped to get into shallow ports where the melters are located ${ }^{2}$.

Nowadays that oil holds a share of a $33.1 \%$ and liquefied natural gas (LNG) is at $23.9 \%$ of the global energy consumption ${ }^{3}$, the procedures of transshipment at sea forms an essential link in the chain of the global movement of energy providing valuable help to the optimization of the distribution plan from the producer to the final consumer ${ }^{4}$. During the transfer procedure, the seagoing ships are positioned alongside each other. Both ships are moving with low speed and the objective cause is to bring their manifolds in line to conduct the transfer of the cargo. Ship to Ship transfer operation can be conducted either stationary or underway depending on different factors such as the selected area for the transfer (shallow or deep waters, efficient room for maneuvers etc) or the weather and sea state conditions ${ }^{5}$. The addition of Chapter 8 to MARPOL (Annex I of the Protocol of 1978 for the Prevention of Pollution from ships) is the first significant action to establish common rules during STS transfer operations ${ }^{4,6}$. Generally, an STS transfer procedure comprises four different phases: the preparation, the mooring phase, the transfer procedure, and the unmooring. Each phase of the STS operations consists of different procedures to follow and checklists to complete. Figure 1 shows the most common STS transfer areas in a worldwide scale.

To complete successfully an STS transfer operation many different parties should cooperate and work together. The parties involved in the operation are the following: the vessels including the masters of each ship, the personnel directly involved to the different phases of the operation and the rest personnel onboard; the STS provider which includes the person overall advisory control (POAC), the STS superintendents and 
the relevant personnel involved to the procedure; the local authorities who participate as an independent observer of the procedure under the condition that the operation is conducted within waters of its jurisdiction. Moreover, other parties that are indirectly involved to an STS operation are the insurers, the charterers, the stakeholders, and the ship and the cargo owners ${ }^{7}$.

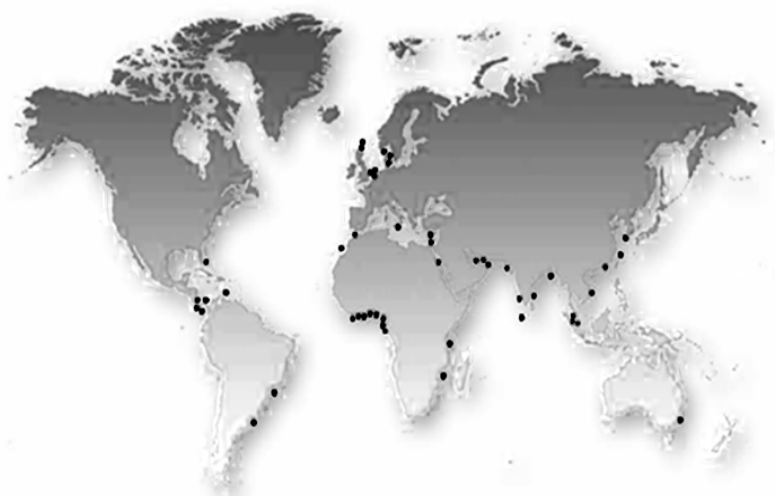

Fig.1. Ship to Ship transfer areas worldwide.

Although these procedure shave been continuously recorded in ${ }^{5}$, nevertheless they remain difficult and they demand the nonstop attention of the industry. To reduce the adverse effect of a potential accident to human health as well as to the environment, a risk assessment is necessary to be done to evaluate the hazards that derive from such difficult procedures. For that purpose, different analysis techniques and methodologies have been developed and applied to assess the hazards of an STS procedure. See Refs. 7 and 8-13 for more details.

Although traditional methods such as Fault Tree Analysis (FTA) or Event Tree Analysis (ETA), have been used to solve problems related to safety or risk analysis, nevertheless they rely on statistical or historical data that may not always be given; thus traditional methodologies may have limited effectiveness $^{14}$. One feasible way to tackle with uncertainty from insufficient or imprecise data is the use of fuzzy logic. The use of linguistic terms to express the expert's judgment or to present the risk in terms of fuzziness helped researchers to develop models to deal with uncertainty. An important brunch of fuzzy logic is the well-known fuzzy inference system (FIS).

The FIS approach, which is under development over the last decades, has been used to solve problems in a human driven way of thinking and language. To this end, the FIS approach has been used for studies in industrial applications; see relevant Refs. 15-17, in computer sciences with corresponding Refs. 18 and 19, in medical research; see Refs. 20-22, in sports ${ }^{23}$ and education $^{24}$, in telecommunications ${ }^{25}$, and in the finance market $^{26}$.

Within the maritime industry, the FIS engine has been applied to the prevention of marine accidents ${ }^{27}$, to evaluate accident senarios ${ }^{28}$ or to conduct safety analysis for marine systems ${ }^{14}$. The aim of this paper is to apply a fuzzy inference system (FIS) as a novel approach to risk assessment for each individual phase of the STS transfer operation. The indisputable advantages of fuzzy approach have mainly to do with the ability to use natural or linguistic terms to express variances of variables while at the same time it provides an effective tool for the treatment or combination of different variables. The most common way to use the fuzzy inference system is through direct methods, such as Mamdani's and Sugeno's methodologies ${ }^{29}$. Finally, a hypothetical scenario of an STS transfer of oily products operation is implemented to evaluate the effectiveness of the proposed FIS approach.

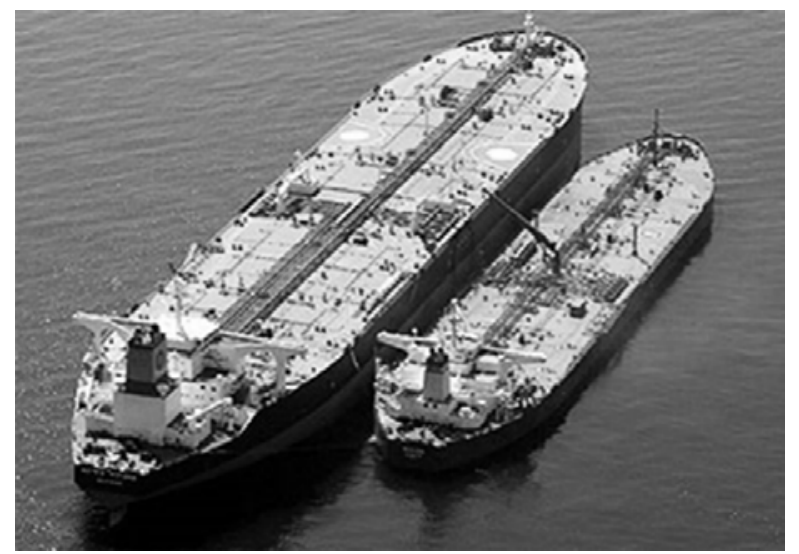

Fig.2. Ship to Ship procedure during the phase of the transfer of cargo.

Fuzzy inference system is applied in order to conduct risk assessment for STS transfer of petroleum products, or liquefied gases (LPG, LNG). To achieve the goals, the paper is organized as following: Section 2 presents an analytical description of the STS transfer operations. For that purpose, sufficient data from the best practice guidelines published from organizations such as the International Chamber of Shipping (ICS), the Oil Companies of International Marine Forum (OCIMF) and the International Maritime Organization (IMO) have been used. Section 3 comprises the theoretical background of the fuzzy inference system methodology. Then, the FIS is applied to an STS transfer operation in Section 4 and the corresponding results are presented in Section 5; In addition, Section 6 discusses the results, and finally Section 7 provides the conclusions of the study. 


\section{Ship to Ship Transfer Operation}

The STS transfer operation consists of four discrete phases all in the context of the safely transfer of cargo from one ship to another. In particular the phases of an STS operation are: the preparation which includes the pre-fixture information and the beginning of operations, the mooring process, the transfer of cargo, and finally the unmooring procedure.

Prior to the start of the operation, certain conditions and requirements should be met to safeguard the success begins is the checking of the equipment related to mooring, such as fenders or mooring lines, or the equipment used for the transfer process such as hoses, and finally the equipment of general use, such as safety devices (IG, ESD systems), boilers, cranes etc. Last but not least, other general requirements, such as the notification of the local authorities, the weather forecast (wind, wave height), or the rendezvous point should be carefully examined and assessed. After the completion of the phase of preparation the "run-in" procedure starts. Figure 3 illustrates the phase of the preparation and its

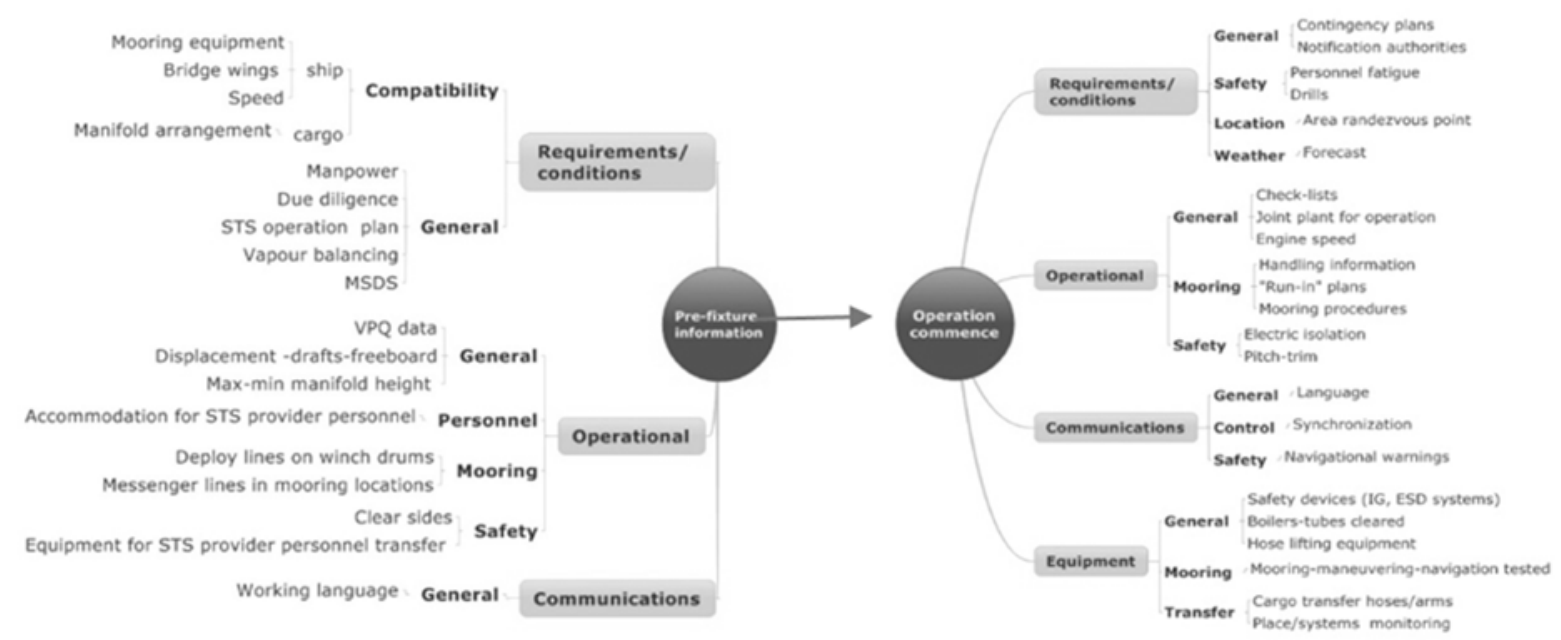

Fig. 3. Mind mapping of the preparation phase of a Ship to Ship transfer operation.

of the entire operation. This pre-fixture information is related to compatibility issues regarding the vessels involved into the operation; hence, information related to the dimensions, freeboard, position of manifolds, mooring equipment and fenders should be thoroughly examined from the masters to ensure that there will not be any problems springing from compatibility issues. Special consideration should be given in the cases in which vessels with similar length are to maintain manifolds in line and at the same time they should avoid bridge wings contact and therefore achieve an optimum mooring arrangement. To this end, the operation may commence only when an overall compatibility assessment in concluded successfully.

Before the operation starts, an operational checking should be done to evaluate the mooring procedures; in addition, the relevant mooring equipment should be certified and the operability of the propulsion system of the vessels should be checked. Special consideration should be given to safety issues (e.g. drills, electric isolation etc.); furthermore, communication issues such as the use of common language and the transmission of emergency signals and warnings should be checked and verified. Another important issue as the operation components

During the phase of mooring operational checking should be done to evaluate the monitoring system of the vessels; also the use of the proper navigational signals and the proper function of the AIS should be certified. Moreover, the personnel involved into the mooring phase should be monitored for readiness and taking their predefined positions (mooring stations, on the bridge etc). Safety issues such as the checking of the side of berthing should be done.

Checking of the STS equipment should be done to safeguard the mooring procedures and the transfer of the cargo. To this direction, fenders (primary and emergency), winches and mooring lines should be carefully examined and tested, if possible. Also the STS transfer equipment such as cargo manifold connections and emergency equipment (axes) should be prepared so as to be ready for use during the next phase of the process. Finally, communication control of the mooring stations is conducted and shipping traffic within the selected location for the STS transfer operation is monitored and assessed. After completion of the phase of mooring the transfer process starts. The description of the mooring phase is illustrated in Figure 4. 


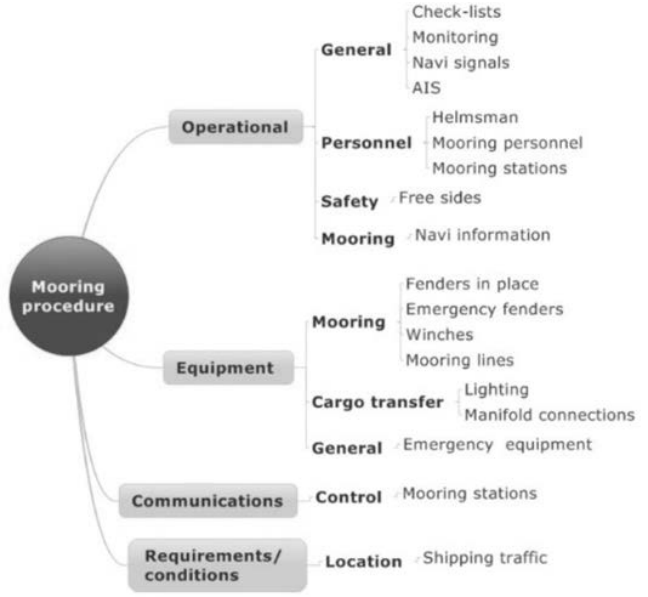

Fig.4. Mind mapping of the mooring procedure of a Ship to Ship transfer operation.

The actual transfer of cargo consists of the operational verification for various issues such as: the control of the initial and the maximum transfer rate, the emergency shutdown transfer procedures, the ballasting and de-ballasting processes etc. Other operational controls are relevant to the monitoring and supervision of the crew for taking their positions according to the STS operation plan; for example, the predefined manned positions are for the engine room, the bridge, the anchor, the manifolds etc. In case of the transfer of liquid cargoes such LPG or LNG, special consideration should be given to cooling, to the vapors and their characteristics (max pressure, rates etc.), and finally to the proper functionality of the EDS system. Moreover, in the case of an LNG transfer, extra consideration should be given for the ESD systems and their functionality, the tightness of the connection lines, and the operability of the nitrogen plant and water protection. After the completion of this phase the unmooring procedure commences. The complete structure of the transfer phase is illustrated in Figure 5.

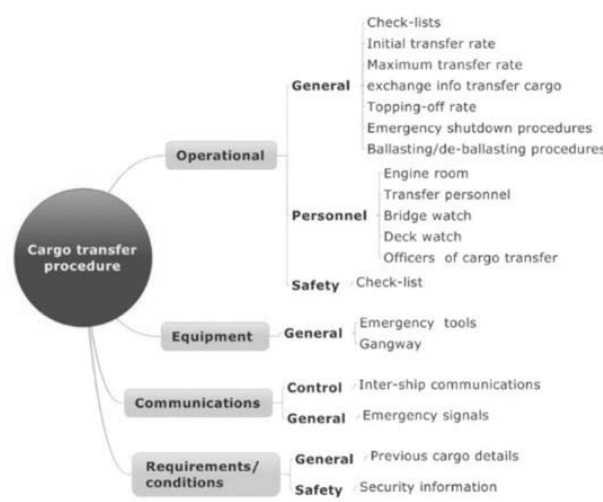

Fig.5. Mind mapping of the transfer procedure of a Ship to Ship transfer operation.
During unmooring, the separation method should be determined and followed; also the cancellation of the navigational warnings and the update of the AIS with regards to the status of the vessels should be performed. The berthing side should be inspected that it is clear and the involved personnel should take their predetermined positions (bridge, mooring stations etc). The relevant equipment should be inspected for operability; the transfer hoses should be disconnected and drained from the manifolds. The mooring equipment, such as the fenders, the winches, and the maneuvering and navigation equipment should be tested for proper future use. In case of LNG transfer, special consideration should be given to the cargo hoses and to the processes of isolation and drain. The complete phase of the unmooring procedure is illustrated in Figure 6.

Although the industry practice is to control the STS operation by the application of precise and accurate procedures, nevertheless the possibility of a potential accident always remain as a threat; hence the determination of the high level risks during each phase of the overall effort is of utmost importance.

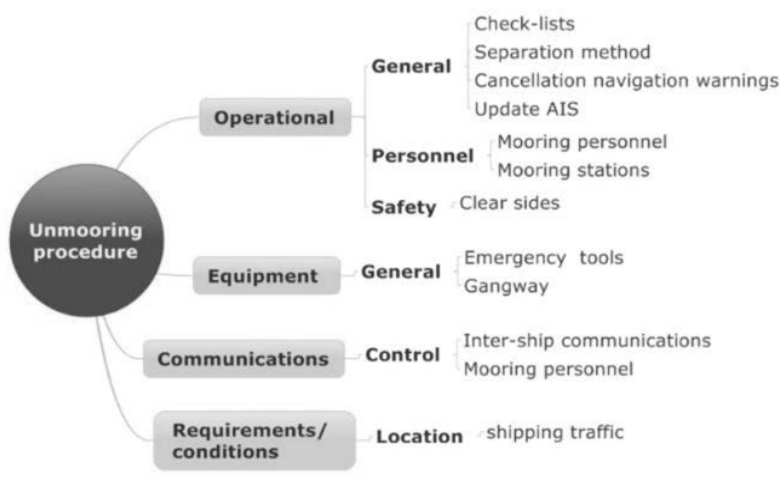

Fig.6. Mind mapping for the unmooring phase of a Ship to Ship transfer operation

Knowing the risks is the first step to develop hypothetical accident scenarios and following to evaluate them in order to take the necessary measures to mitigate or alleviate their effect. To do so, the best practice guidelines published from organizations such as ICS, OCIMF and IMO have been used in addition to previous studies and relevant researches. High level risks are considered those that may lead to the abortion of the STS transfer procedure. The aforementioned risks can be categories according to their possible effect as a threat; hence there are risks relevant to the human 
element, risks relevant to the environment and risks relevant to the property.

In the light of the above, the high level risks during an STS operation are collision between the involved vessels, cargo leakage on deck, pollution, damage to cargo tanks, accident during personnel transfer, accident during mooring/unmooring operations or fire on deck or/and explosion. A careful consideration of the aforementioned high level risks can provide valuable information about the causes that may lead an incident, to escalate to accident during the development of an STS transfer operation. To this end data retrieved from investigations of previous accidents during STS transfer operations shows that the factors that affect the operation are the vessel's compatibility, the relevant experience of the masters and the crew involved, the skills and qualifications of the STS provider that is responsible to provide equipment and staff for the operation and finally the prevailing environmental conditions during the operation. These factors will be developed in details in session 4.

\section{Background of Fuzzy Inference System Theory}

The indisputable complexity of maritime activities due to the difficult and in many times hostile environment, in combination with the public concern regarding to the possibility of a marine accident with adverse environmental effect, led to the study and development of advance methods to mitigate, or even eliminate the possibility of a potential marine accident. Both traditional and sophisticated methods have been used to identify the potential hazards or to address the possible accident scenarios; the latter is the first step to conduct risk analysis with the objective cause to alleviate the probability of an accident.

One significant problem that someone has to deal with during a risk assessment analysis is the reliability of the employed data. Many times the records that are used to conduct risk assessment for a marine system ${ }^{12}$, ${ }^{14}$ are vague and imprecise the uncertainty that derives from imprecise data remains a serious consideration for the standards of the research. One feasible way to tackle with uncertainty from insufficient or imprecise data is the use of fuzzy logic. Fuzzy logic was first introduced from L.Zadeh ${ }^{30}$ back in the 1960's; the basic concept was to rely on the fuzziness of human perception by using linguistic descriptions to express decision variables. This unique feature to interfere between objective and human perceptive reality, led fuzzy logic to great development over the last decades.

The basic principle of applying FIS is to solve problems througha more human way of thinking and with the usage of linguistic terms. The advantages of a fuzzy approach have mainly to do with the ability to use natural or linguistic terms to express the variances of variables while at the same time, it provides an effective tool for the treatment or combination of different variables. The most common way to use FIS is through direct methods, such as the Mamdani's method. Hence, the FIS is a challenging way to apply fuzzy inference systems for the risk assessment of maritime activities. Previous works have shown ${ }^{14,27,28}$ that the use of FIS for risk assessment can provide a valuable tool in the hand of experts.

\subsection{The theoretical background of the fuzzy inference system approach}

The FIS is a process of producing a certain output from a given set of inputs using fuzzy logic. The mechanism to produce the output from inputs is shown schematically in Figure 7 and it consists of the following steps ${ }^{29}$ :

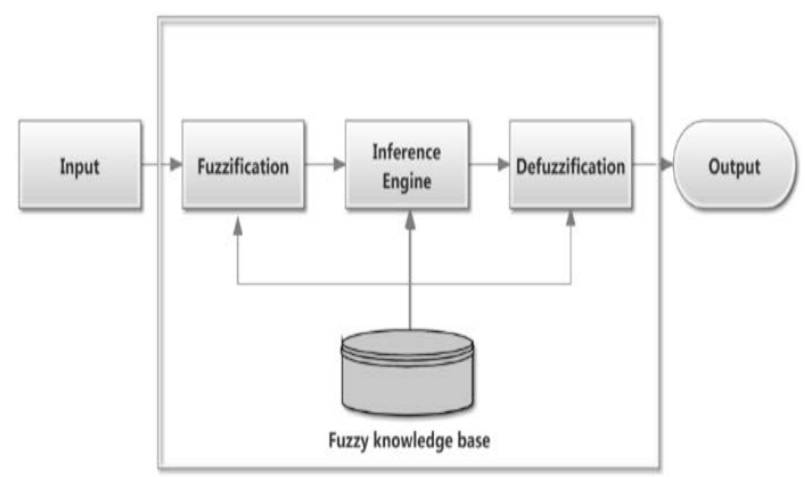

Fig.7. Flow diagram of a Fuzzy Inference System engine ${ }^{29}$.

- Fuzzification: The input variables are converted from crisp values to linguistic values using the proper membership functions stored in the fuzzy knowledge base. During this phase, the degree of relation of the crisp values to the fuzzy sets is determined.

- Inference engine: The linguistic variables are used as inputs to the fuzzy engine where under the influence of fuzzy rules "If-then" they are converted to fuzzy output. If the antecedent of a rule consists of two or more parts, a fuzzy operation is applied to obtain the result of the antecedent of the rule. Before applying the operations the rule's weight should be determined. Finally the fuzzy outputs of the inference engine are aggregated to a fuzzy number for each individual input parameter.

- Defuzzification: The aggregated fuzzy number is converted to crisp value by using membership 
functions similar to those used during fuzzification. The most popular defuzzification method is the centroid calculation, which returns the value of the center of gravity of area under the curve. The overall procedure of a FIS sequence is presented in Figure 8.

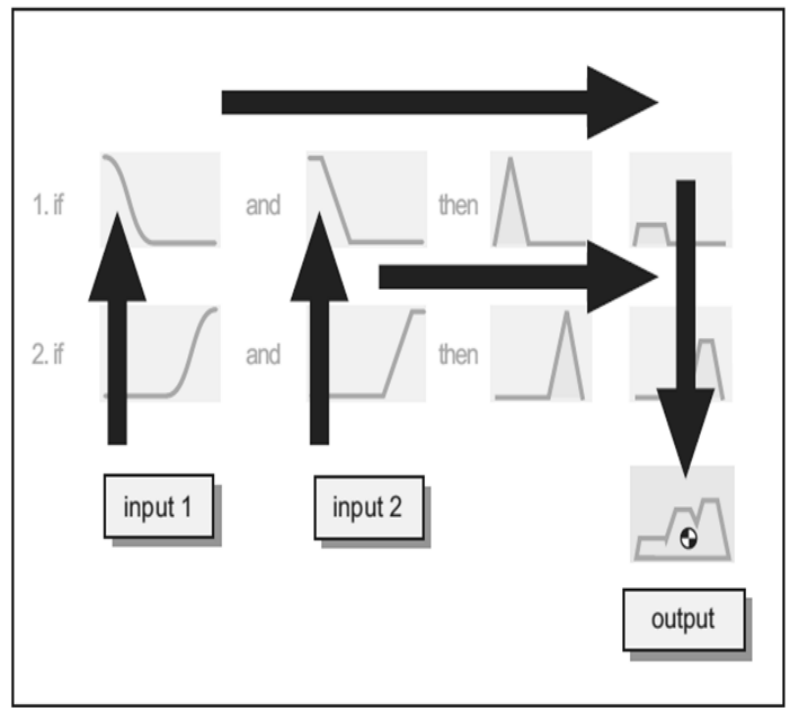

Fig.8.Interpreting the fuzzy inference diagram ${ }^{29}$.

\subsection{The Mamdani's methodology}

The Mamdani's method is probably the most known FIS process in fuzzy set theory. It was proposed in 1975 by Ebrahim Mamdani as an attempt to control a the combined set up of a steam engine and a boiler by synthesizing a set of linguistic control rules obtained from experienced human operators ${ }^{31}$. In the Mamdanitype inference, the output membership functions are fuzzy sets.

This study uses the Matlab ${ }^{\circledR}$ toolbox for fuzzy inference system (FIS) to implement Mandani’s methodology for STS transfer operations. The Matlab ${ }^{\circledR}$ toolbox is depicted by Figure 9 and it comprises the following tools $^{29}$ :

- Fuzzy Inference System (FIS) Editor: the editor is used to insert the variables to the FIS engine.

- Membership Function Editor: this editor is used to define the shapes of all the membership functions associated with each variable.

- Rule Editor: this editor is used to insert the rules and also to weight each one to define the behavior of the system.

- Rule Viewer: this editor is used to depict the fuzzy inference diagram. It is also used as a diagnostic tool to see how the fuzzy engine works.
- Surface Viewer: this editor is to view the dependency of the output regarding to each one of the inputs separately and it also generates and plots an output surface map for the system.

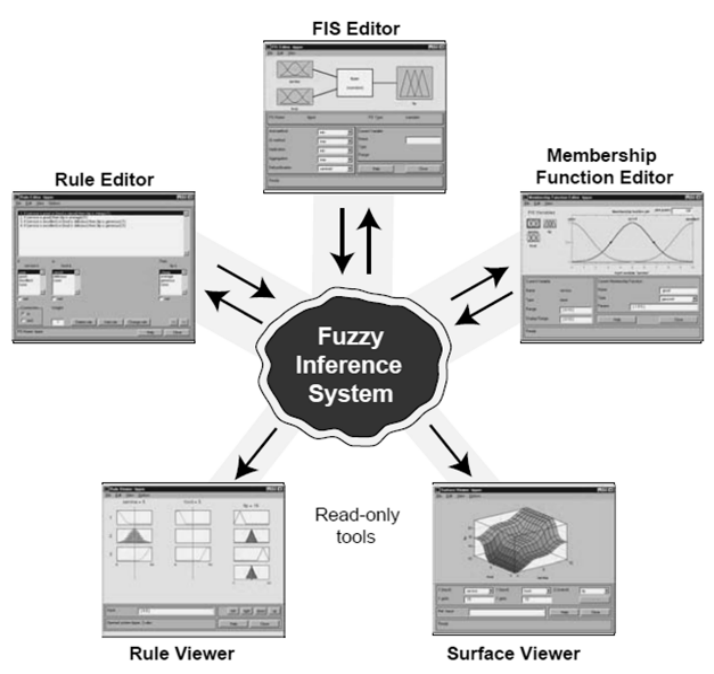

Fig. 9. The toolbox of fuzzy inference system in Matlab ${ }^{\circledR 2}$.

\section{Implementation of Mamdani's Methodology for Ship to Ship Transfer Operations}

To implement Mamdani's methodology to STS transfer operations the input parameters of the FIS engine are selected among the different factors that interact with each other during such operations and may potentially contribute to the occurrence of an accident; hence an STS transfer operation involves in a direct or indirect way the following parties ${ }^{4}$ :

- The vessels compatibility, which includes vessel's and cargo's compatibility (dimensions, propulsion installations, mooring and anchorage equipment, personnel transfer equipment etc.) (Figure 10).

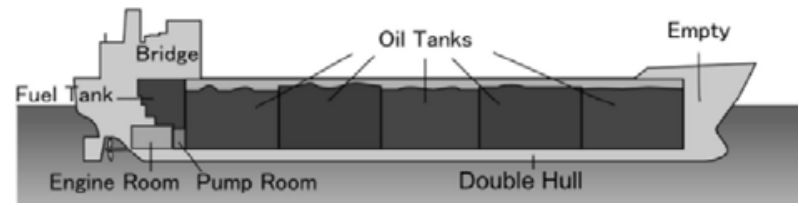

Fig.10. The profile (section) of an oil tanker. For Ship to Ship operations with ships of similar classification special consideration is given for mooring arrangement, fenders selection and technical issues such as bridge wings or fuel tanks and engine room protection in case of collision 
Table 1a.Classes of recorded tanker vessels conducting Ship to Ship operations ${ }^{33}$.

DWT=Deadweight tonnage

\begin{tabular}{|l|l|l|l|l|l|l|}
\hline No & Class & $\begin{array}{l}\text { Length } \\
(\mathbf{m})\end{array}$ & $\begin{array}{l}\text { Beam } \\
(\mathbf{m})\end{array}$ & Draft (m) & $\begin{array}{l}\text { Typical Min } \\
\text { DWT (tn) }\end{array}$ & $\begin{array}{l}\text { Typical Max } \\
\text { DWT (tn) }\end{array}$ \\
\hline 1 & Seawaymax & 226 & 24 & 7.92 & 10.000 & 60.000 \\
\hline 2 & Panamax & 228.6 & 32.3 & 12.6 & 60.000 & 80.000 \\
\hline 3 & Aframax & 253.0 & 44.2 & 11.6 & 80.000 & 120.000 \\
\hline 4 & Suezmax & 274.1 & 46.0 & 16 & 120.000 & 200.000 \\
\hline 5 & VLCC & 330 & 58 & 20 & 200.000 & 320.000 \\
\hline 6 & ULCC & 458.45 & 68.8 & & 320.000 & 550.000 \\
\hline
\end{tabular}

To this end, the majority of STS transfer operations (about $80 \%$ ) involves the ship classes ${ }^{43}$ shown in Table 1a. Furthermore, many of the hazards during the STS operation are considered to be in conjunction with tanker size ${ }^{32}$.This means that STS transfer operation between for example an Aframax and a Suezmax classification vessel is safer from those between a ULCC and a Suezmax.

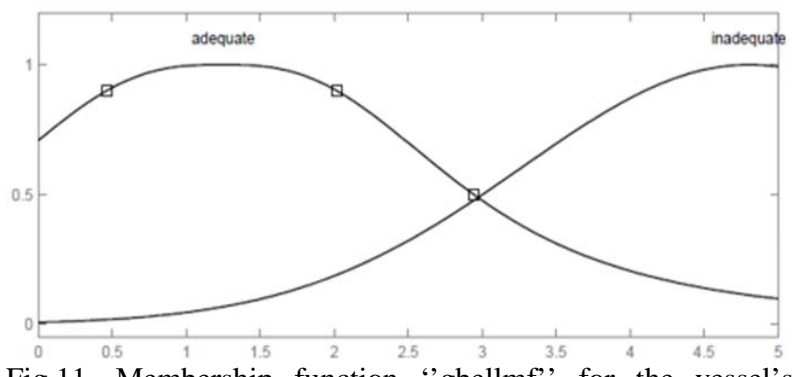

Fig.11. Membership function "gbellmf" for the vessel's compatibility variable

Moreover, the guidance from OCIMF $^{5}$ gives special consideration to STS operations between ships of similar classification due to issues related to mooring arrangement and ships general arrangement (bridge wings etc.). The presented study in this paper assumes that each ship according to her class comply with the general requirements for STS transfer operations regarding to manifold arrangement, sufficient manpower, bridge wings and mooring equipment. A bell shaped membership function (MF) which expresses the vessel's compatibility according to their size class is applied; the corresponding MF was chosen because it simulates better than others the corresponding class values; it is presented in Figure 11.

Table 1b. Classification of tanker ships.

\begin{tabular}{|l|l|l|}
\hline $\begin{array}{l}\text { Difference } \\
\text { of class }\end{array}$ & Level & $\begin{array}{l}\text { Definition of } \\
\text { possibility for an } \\
\text { accident to occur }\end{array}$ \\
\hline $0-3$ & 1 & Adequate \\
\hline $4-5$ & 3 & Inadequate \\
\hline
\end{tabular}

- The masters and crews involved in the procedure and their individual training/ experience with regards to STS transfer operations. According to the IMO Resolution MEPC 186(59)/2009 entered into force on April 1st, 2012 the master has always the full responsibility for the STS operations onboard the ship. Moreover, training of the crew involved into STS procedures is critical especially when emergency conditions arise. It is of high importance to prepare adequately the crew prior to the operation in relation to both emergency transfer procedures and emergency propulsion procedures. The necessary equipment for navigation must be functional and should be checked before an STS operation ${ }^{4}$. From previous experience to such operations it is assumed that a dedicated vessel can conduct a maximum number of 10 STS transfer operations per year; hence the experience of the master and the crew may be considered to be proportional to the number of STS transfers that they have in their track record. A bell shaped MF which expresses the master and crew experience is applied; the corresponding scale is shown in Table 3, whereas the MF is presented in Figure 12.

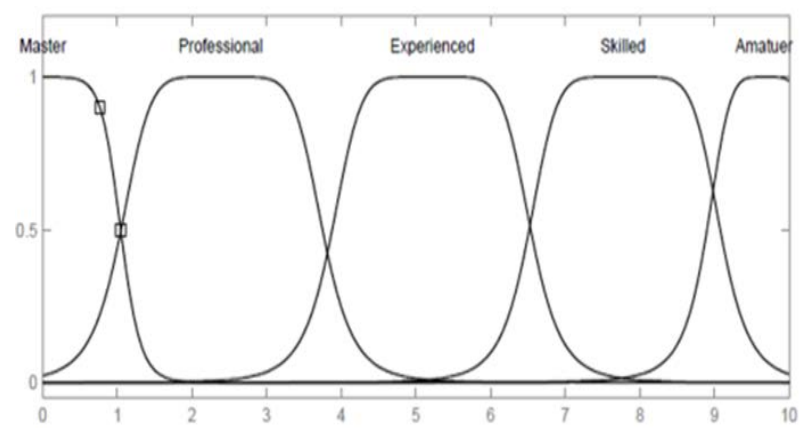

Fig.12. Membership function 'gbellmf" for the master's and crew experience variable

- The STS provider is responsible to provide the STS equipment as well as the Person OverAll Advisory Control (POAC). The equipment that is necessary for the conduction of the operation consists of tugs, main and secondary fenders transfer hoses etc ${ }^{1}$. The 
Table 2. Reference guide for fender selection from Ref. 5.

\begin{tabular}{|c|c|c|c|c|}
\hline $\begin{array}{l}\text { C } \\
\text { Berthing } \\
\text { Coefficient } \\
\text { (Tonnes) }\end{array}$ & $\begin{array}{l}\text { Approach } \\
\text { Velocity } \\
\text { (m/Sec) }\end{array}$ & $\begin{array}{l}\text { Berthing Energy } \\
\text { (Tonnes.m) }\end{array}$ & $\begin{array}{l}\text { Suggested } \\
\text { Fenders } \\
\text { (Quantity) }\end{array}$ & $\begin{array}{l}\text { Typical HP } \\
\text { Pneumatic } \\
\text { Fender (50kPa) } \\
\text { (Metre) }\end{array}$ \\
\hline 1,000 & 0.30 & 002.4 & 3 or more & $1.0 \times 2.0$ \\
\hline 3,000 & 0.30 & 007.0 & 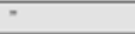 & $1.5 \times 3.0$ \\
\hline 6,000 & 0.30 & 014.0 & - & $2.5 \times 5.5$ \\
\hline 10,000 & 0.25 & 017.0 & 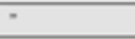 & $2.5 \times 5.5$ \\
\hline 30,000 & 0.25 & 040.0 & 4 or more & $3.3 \times 6.5$ \\
\hline 50,000 & 0.20 & 048.0 & 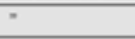 & $3.3 \times 6.5$ \\
\hline 100,000 & 0.15 & 054.0 & 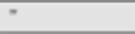 & $3.3 \times 6.5$ \\
\hline 150,000 & 0.15 & 071.0 & 5 or more & $3.3 \times 6.5$ \\
\hline 200,000 & 0.15 & 093.0 & 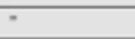 & $3.3 \times 6.5$ \\
\hline 330,000 & 0.15 & 155.0 & 4 or more & $4.5 \times 9.0$ \\
\hline 500,000 & 0.15 & 231.0 & 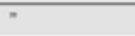 & $4.5 \times 9.0$ \\
\hline
\end{tabular}

choice of the proper equipment is of utmost importance. The size of the pneumatic fenders, as well as their arrangement on the involved ships should be in proportion with the vessel's selection. The OCIMF recomendations ${ }^{5}$ provide a quick guide regarding to the fender selection. According to Ship to Ship transfer guide ${ }^{5}$ of OCIMF, Table 2, should be used with considerable caution based on the knowledge and experience of the type of the STS transfer operation; hence the choice of the proper fender equipment should not be considered as a trivial task but it is in conjunction with the accumulated experience of the STS transfer provider.The hose selection, in case of use from STS provider equipment should also be done with special consideration; hence previous experience to STS operations of the provider is crucial.

Table 3. Scale of the master's and crew experience

\begin{tabular}{|c|l|l|}
\hline $\begin{array}{l}\text { Level of } \\
\text { experience }\end{array}$ & Degree & $\begin{array}{l}\text { Masters and crew experience per } \\
\text { year }\end{array}$ \\
\hline 1 & Master & $\begin{array}{l}\text { Expert master and crew in STS } \\
\text { transfer operation. They are } \\
\text { involved in more than 9 STS } \\
\text { operations per year }\end{array}$ \\
\hline 3 & Professional & $\begin{array}{l}\text { Good experience in STS transfer } \\
\text { operations. They are involved in 7 } \\
\text { to 8 STS operations per year. }\end{array}$ \\
\hline 5 & Experienced & $\begin{array}{l}\text { Low experience in STS transfer } \\
\text { operations. They are involved in 5 } \\
\text { to 6 STS operations per year. }\end{array}$ \\
\hline 7 & Skilled & $\begin{array}{l}\text { Low experienced master and crew } \\
\text { to STS transfer operations. They } \\
\text { are involved in 3 to 4 STS } \\
\text { operations per year. }\end{array}$ \\
\hline 9 & Amateur & $\begin{array}{l}\text { Inexperienced master and crew to } \\
\text { STS transfer operations. They are } \\
\text { involved in less than 2 STS } \\
\text { operations. }\end{array}$ \\
\hline
\end{tabular}

In general, it is assumed that the choice of the right equipment and moreover it's proper use (e.g. the fender arrangement) for STS transfer operation regarding to fenders, hoses or other peripheral components is in conjunction to the previous experience of the STS provider to STS operations; thus the possibility of an accident occurrence is analogous to the previous experience of the STS provider. From statistical data Fender care marine (FCM), which is one of the five largest global providers of STS services conducts about 2700 per year according to Ref. 34. According to the IMO resolution MEPC 186(59)/2009 the objective of the

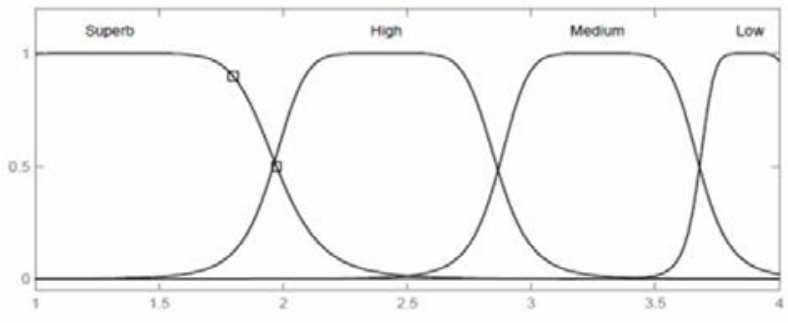

Fig. 13. The membership function "gbellmf" of Ship to Ship provider experience-suitable equipment variable

Person of the Overall Advisory Control (POAC) is to complete the STS transfer operation safely and in accordance with the regulations set by IMO (OCIMF, 2013). His role is of crucial importance and for that reason POAC should have an appropriate management level deck license or a certificate respective international certification standards; he also should comply with the regulations and guidelines of the relevant ILO, IMO and national regulations regarding to the resting hours in order to maintain his readiness and alertness. It is assumed the STS provider experience to select the proper equipment is analog to the POAC's experience; a bell shaped MF which expresses the STS provider's relevant experiencesuitable equipment is applied; the scale for the STS 
provider experience is shown in Table 4. The relative MFs are presented in Figure 13.

Table 4. The implemented scale of the STS provider relative importance.

\begin{tabular}{|c|c|l|}
\hline $\begin{array}{c}\text { Level of } \\
\text { Experience }\end{array}$ & $\begin{array}{c}\text { STS } \\
\text { operations } \\
\text { per year }\end{array}$ & \multicolumn{1}{|c|}{$\begin{array}{c}\text { Definition of possibility for an } \\
\text { accident to occur }\end{array}$} \\
\hline 1 & $2000-3000$ & $\begin{array}{l}\text { Superb level of experience in STS } \\
\text { transfer operations. Excellent } \\
\text { knowledge of choosing the suitable } \\
\text { equipment. Minimum failure } \\
\text { possibility. POAC with expert } \\
\text { qualifications and experience of } \\
1000-2000 \text { STS operations. }\end{array}$ \\
\hline 2 & $1000-2000$ & $\begin{array}{l}\text { High level of experience in STS } \\
\text { transfer operations. High } \\
\text { knowledge of choosing the suitable } \\
\text { equipment. Low failure possibility. } \\
\text { POAC with expert qualifications } \\
\text { and experience of 500-1000 STS } \\
\text { operations. }\end{array}$ \\
\hline 3 & $100-1000$ & $\begin{array}{l}\text { Medium level of experience in STS } \\
\text { transfer operations. Adequate } \\
\text { knowledge of choosing the suitable } \\
\text { equipment. Medium failure } \\
\text { possibility. POAC with expert } \\
\text { qualifications and experience of } \\
\text { 100-500 STS operations. }\end{array}$ \\
\hline 4 & $\begin{array}{l}\text { Low level of experience in STS } \\
\text { transfer operations. Inadequate } \\
\text { knowledge of choosing the suitable } \\
\text { equipment. Maximum failure } \\
\text { possibility. POAC with expert } \\
\text { qualifications and experience of 0- } \\
\text { 100 STS operations. }\end{array}$ \\
\hline $0-100$
\end{tabular}

- The environmental conditions is a factor that affect the STS transfer operation in a direct way; selected transfer area (traffic density, geological factors, security threat, underwater pipelines and/or cables, water depth) as well as weather and environmental conditions (sea state, wind, tidal currents, visibility etc.) plays an important role during the STS operation. Among them, weather conditions are of critical importance; moreover, operations in darkness are important to be avoided due to the significant increase of accident hazards.

It is assumed that the limits for STS operations are according to the FCM information; for mooring operations the limit for wind is 25 knots which equals about 13 meters per second, whereas for the transfer procedure the respective limit is 35 knots, which equals about 18 meters per second. For swells/seas, the limit reaches 2 to 3 meters.

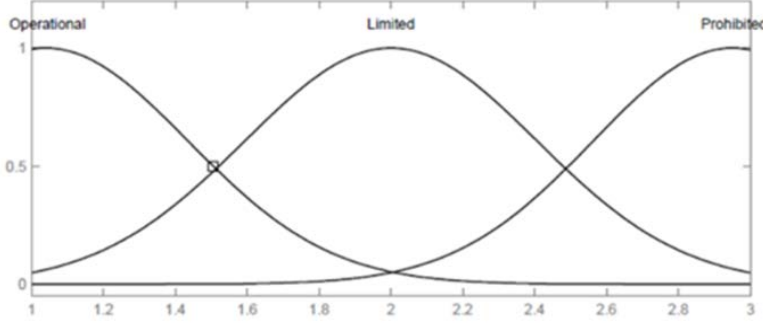

Fig.14. Membership function 'gaussmf' of environmental conditions variable

Furthermore, incident statistics given from STS provider $^{35}$ for a period between 2011-2013 the average indicate that wave height has an adverse effect to the operation. To this end the environmental factor is defined as shown in table 5; a bell shaped MF which expresses the prevailing environmental conditions is applied; the corresponding scale of the prevailing environmental conditions is shown in Table 5 as well as the relevant MF is presented in Figure 14.

Table 5. Scale of the prevailing environmental conditions

\begin{tabular}{|c|c|l|}
\hline Level & Description & \multicolumn{1}{|c|}{ Definition } \\
\hline 1 & Operational & $\begin{array}{l}\text { Operations during daylight with wind } \\
<25 \mathrm{knots} \text { and good environmental } \\
\text { conditions. Average wave height }<0.5 \mathrm{~m}\end{array}$ \\
\hline 2 & Limited & $\begin{array}{l}\text { Operations during daylight with wind 25 } \\
\text { to } 35 \mathrm{knots} \text { and good environmental } \\
\text { conditions or operation during night } \\
\text { Average wave height } 1.5 \mathrm{~m}<\mathrm{h}<0.5 \mathrm{~m}\end{array}$ \\
\hline 3 & Prohibited & $\begin{array}{l}\text { Operations during daylight with wind } \\
>35 \mathrm{knots} \text { and adverse environmental } \\
\text { conditions. Average wave height }<1.5 \mathrm{~m} .\end{array}$ \\
\hline
\end{tabular}

\section{Results}

This study employs a FIS (on the Matlab toolbox) to assess the risk of different combinations for four basic factors which affect an STS transfer of cargo. In particular, the Mamdani's methodology is applied for the STS transfer operations. The input variables (factors) are: the vessels compatibility according to the classification of the ships involved; the relative experience to STS operations of the master and crew; the experience of the STS provider which concludes the qualifications of the person over all advisory control (POAC) and the suitability of the selected equipment for the STS operation (fenders, hoses etc); and finally the prevailing environmental conditions which are mainly reflected by weather conditions and the sea state. The FIS structure shown in figure 15, displays the fuzzy inference engine with the four input variables/factors on the left, and the output variable of risk during STS transfer operations on the right hand side. 


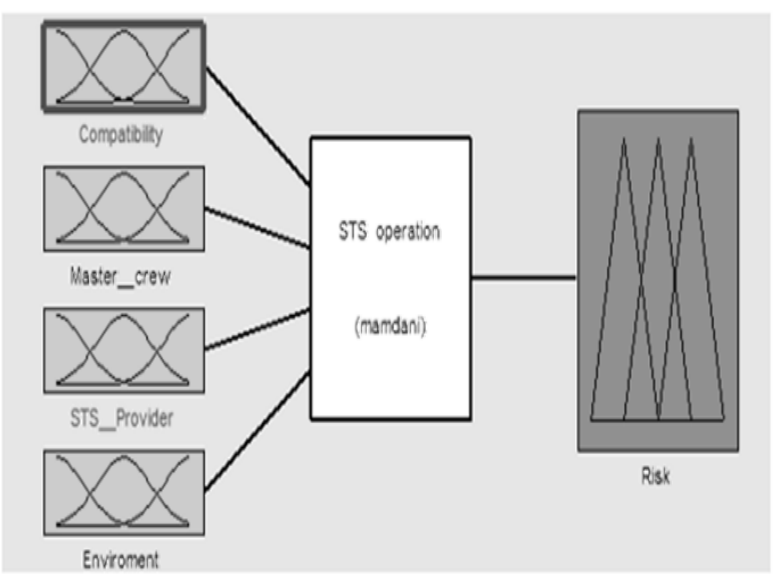

Fig.15.The structure of the fuzzy inference system with the selected (four) input variables/factors and the one output.

The choice of the most suitable MF in a fuzzy set approach is a crucial issue that is related to the available data and it has concerned many researchers over the years $^{36,37,3840}$. Inference systems can be successfully applied to control systems, or expert systems ${ }^{36}$ or even prediction systems ${ }^{37}$. Nevertheless, the majority of the published work concerning the choice of the suitable MF is related to control systems; see relevant Refs. 3840.

Table 6a. Experts' opinion of the evaluation of the risk associated with the vessels compatibility and the Master's and crew experience.

\begin{tabular}{|l|c|c|}
\hline & Adequate & Inadequate \\
\hline Master & L & L \\
\hline Professional & L & M \\
\hline Experienced & M & M \\
\hline Skilled & H & H \\
\hline Amateur & H & H \\
\hline
\end{tabular}

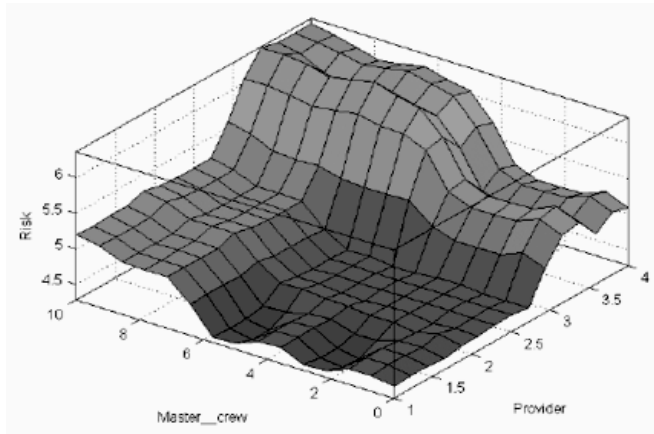

Table 6b. Experts' opinion of the evaluation of the risk associated with the environmental conditions and the Master's and crew experience.

\begin{tabular}{|l|c|c|c|}
\hline & Operational & Limited & Prohibited \\
\hline Master & L & M & H \\
\hline Professional & L & M & H \\
\hline Experienced & M & M & H \\
\hline Skilled & M & H & H \\
\hline Amateur & H & H & H \\
\hline
\end{tabular}

Table 6c. Experts' opinion of the evaluation of the risk associated with the environmental conditions and the vessel's compatibility.

\begin{tabular}{|l|l|l|}
\hline & Adequate & Inadequate \\
\hline Operational & L & M \\
\hline Limited & M & M \\
\hline Prohibited & H & H \\
\hline
\end{tabular}

Table 6d. Experts' opinion of the evaluation of the risk associated with the Master's and crew experience and the STS provider experience.

\begin{tabular}{|l|l|l|l|l|}
\hline & Superb & High & Medium & Low \\
\hline Master & L & M & M & H \\
\hline Professional & L & M & M & H \\
\hline Experienced & L & M & H & H \\
\hline Skilled & M & M & H & H \\
\hline Amateur & H & H & H & H \\
\hline
\end{tabular}

Table 6e. Experts' opinion of the evaluation of the risk associated with the Ship to Ship provider experience and the vessel's compatibility.

\begin{tabular}{|l|l|l|}
\hline & Adequate & Inadequate \\
\hline Superb & L & M \\
\hline High & L & M \\
\hline Medium & M & H \\
\hline Low & H & H \\
\hline
\end{tabular}

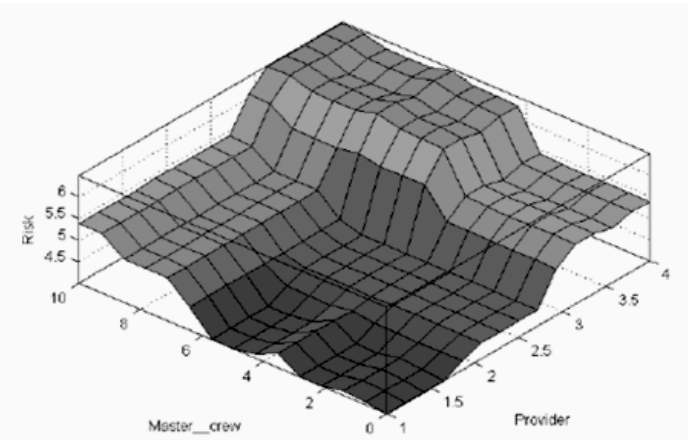

Fig. 16. (Left) Relevant risk from piece-wise linear membership functions. (Right): Relevant risk from Gaussian distribution membership functions. 
Table 6f. Experts' opinion of the evaluation of the risk associated with the Ship to Ship provider experience and the Master's and the environmental conditions.

\begin{tabular}{|l|l|l|l|}
\hline & Operational & Limited & Prohibited \\
\hline Superb & L & M & H \\
\hline High & L & M & H \\
\hline Medium & M & H & H \\
\hline Low & H & H & H \\
\hline
\end{tabular}

In this study, MFs generated from the Gaussian distribution function have been finally selected instead of piece-wise linear functions; as for example figure 16 shows the mapping of the Master and crew experience against the STS provider experience for the estimation of risk during STS operations. The left part of figure 16 uses piece-wise linear MFs, whereas the right part of figure 16 uses MFs generated by a Gaussian distribution function; hence, the Gaussian distribution generates more smooth results without (or with much fewer) irregularities. In addition, the experts have evaluated the relative importance between the input variables and the potential risk so as to introduce the rules to the rules editor. To do so, experts have been asked to rate with a scale of low, medium and high, the risk associated to different combinations of the factors under consideration. The results for the different combinations of the corresponding factors are illustrated in table 6 .

Figure 17 shows three dimension (3D) surfaces as the results of the implementation of the FIS theory to evaluate the risk potential during the STS transfer operation. In particular, different scales of grey indicate the different magnitudes of the associated risk, i.e. from an intense grey scale, areas with low risk potential, to a moderate grey, and a light grey scale, which indicates areas of high level of risk potential.

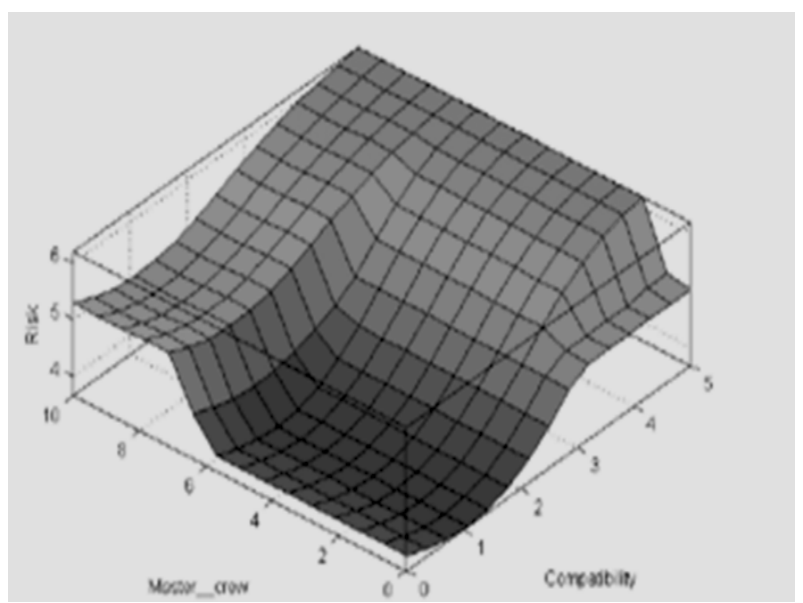

Fig. 17a. The risk mapping based on the Master and crew experience against the Compatibility of vessels

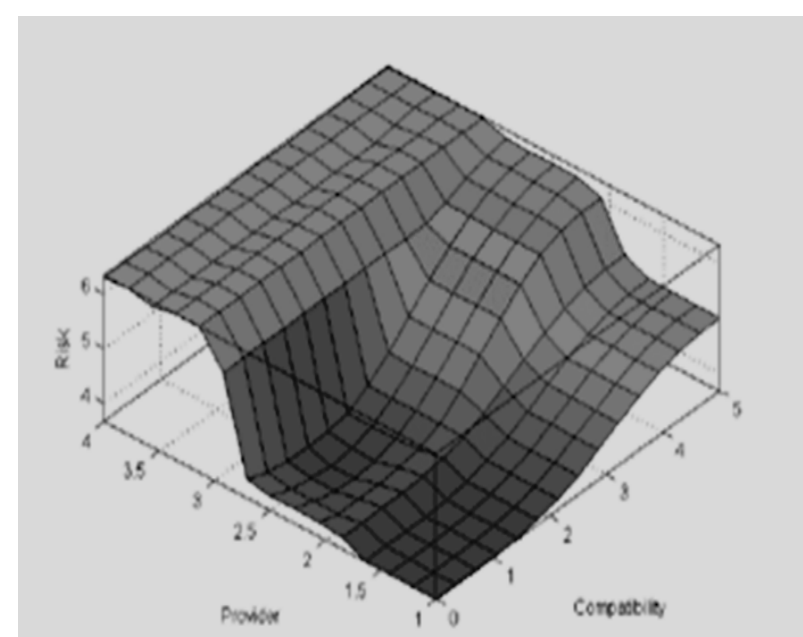

Fig.17b. The risk mapping based on the Ship to Ship provider experience against the Compatibility of vessels.

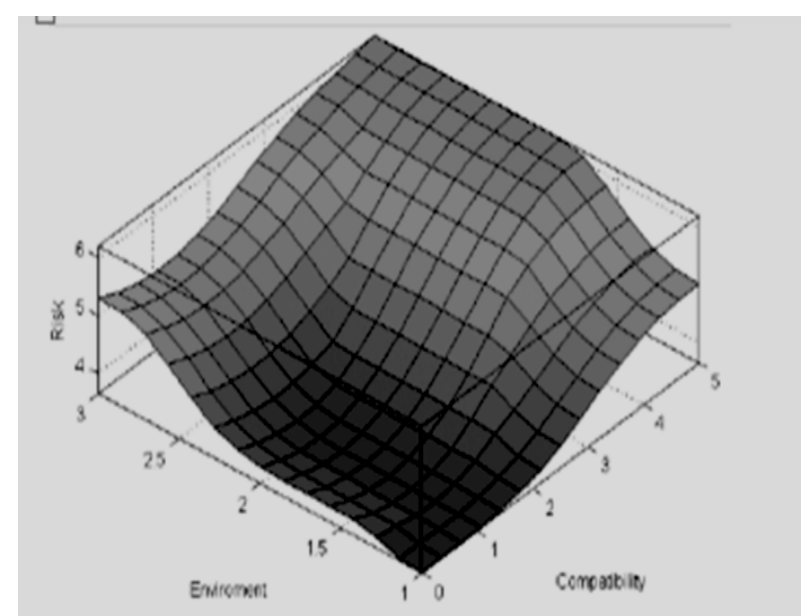

Fig.17c. The risk mapping based on the environmental conditions against the Compatibility of vessels.

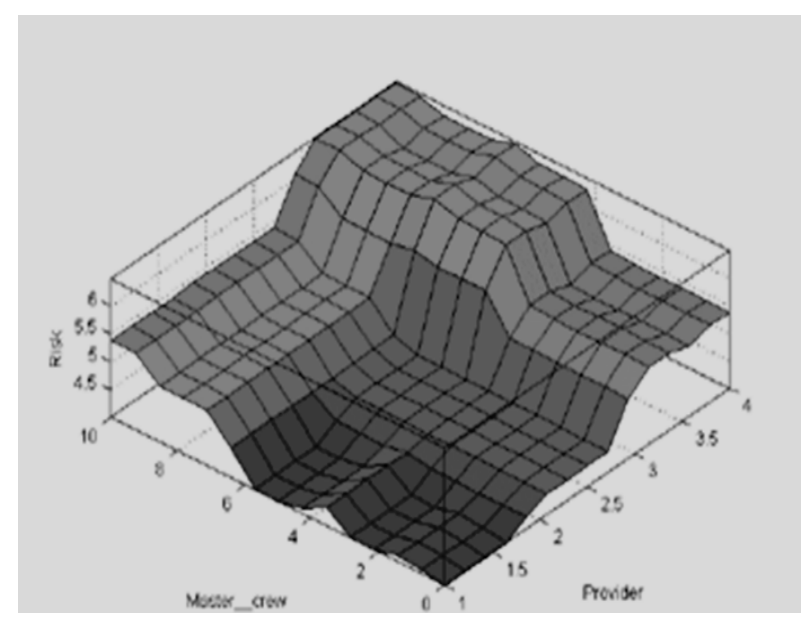

Fig.17d. The risk mapping based on the Master and crew experience against the Provider's experience. 


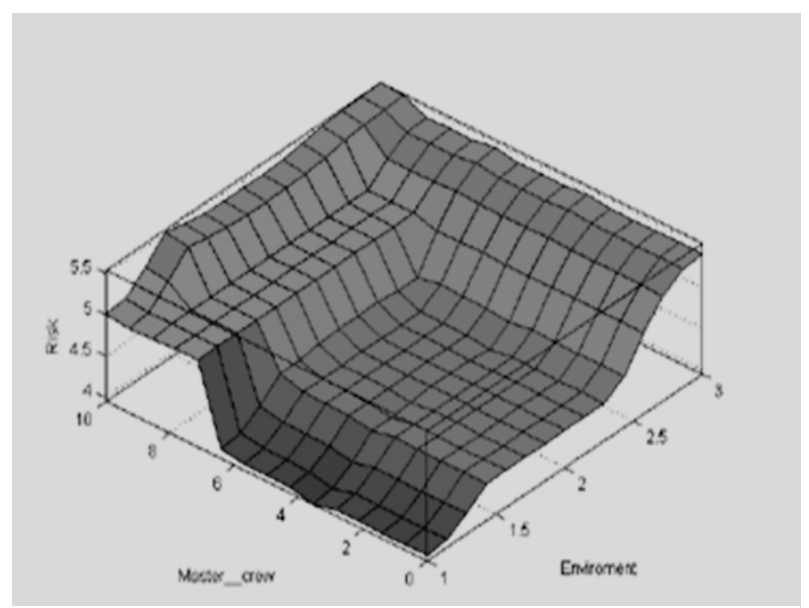

Fig.17e. The risk mapping based on the Master and crew experience against the Environmental conditions.

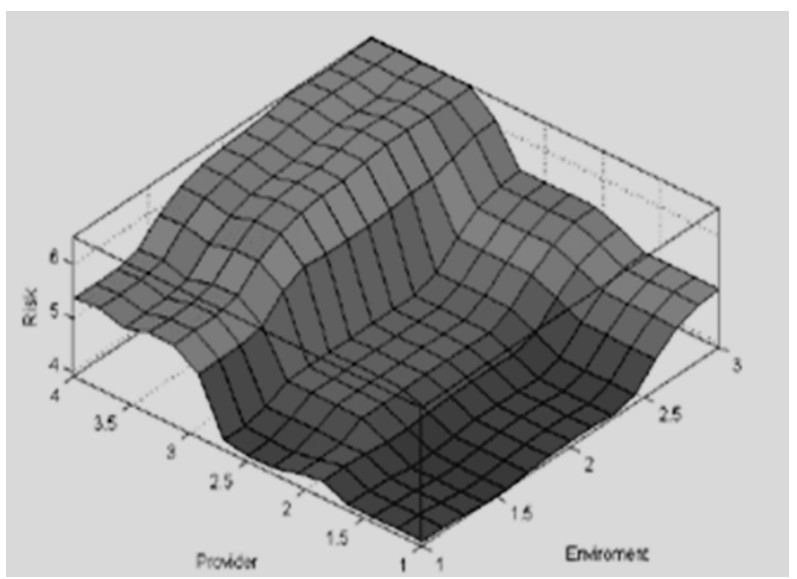

Fig.17f. The risk mapping based on the environmental conditions against the Ship to Ship provider experience.

\section{Discussion}

The risk and safety analysis with respect to STS transfer operations always remains a significant issue within the chain of marine safety. Many studies have focused on this topic by the development of models to conduct an efficient risk assessment; for example, the work from Elsayedin Refs. 12, 28 and 41 or the work of Christensen in Ref. 42focus on risk assessment of marine operations regarding LNG operations, while the work of Loer in Ref. 43 focuses on risk assessment for marine operations regarding petroleum products.

In this study,a FIS methodology has been applied as a novel approach to determine the special relationships of four different factors in the field of assessing the risk of an STS transfer operation: the vessel's compatibility, the master's and crew experience, the STS provider qualifications and the environmental conditions. The results of the analysis demonstrate that MFs associated with each variable based on the Gaussian distribution function instead of piece-wise linear functions indicate the generation of better results in three dimension mapping of the risk associated to the input variables. In particular, the use of Gaussian as well as two-side Gaussian MFs instead of triangular membership functions gives better results without irregularities with respect to the $3 \mathrm{D}$ mapping of the risk potential during STS operations. The use of trapezoidal MFs yields better results than the triangular onestaking into account their smooth continuity; hence these are closer to the ones produced by the Gaussian based MFs. This is due to their smoothness that consequently leads to the generation of better results. The final choice to apply the Gaussian MFs has been made, taken into consideration the overall performance of the employed FIS.

Hence, for the implementation of the FIS model seventy one rules have been applied to the rule editor according to the experts' opinion for all possible combinations of the input variables as shown in table 6 . The results of the analysis are presented with the 3D surfaces in figures 17a to $17 \mathrm{f}$. More specifically, each of these figures depicts the distribution of the risk against the combination of two individual factors;for example figure 17c depicts the risk against the combination of the environmental conditions and the vessel's compatibility. It is obvious that the deterioration of the environmental conditions (wind velocity or/and wave height), in combination with vessels of different classes has an adverse effect to the risk evaluation for STS transfer operations.

Table 7. The evaluation of the selected factors for the Ship to Ship operation from the Master of the Panamax vessel.

\begin{tabular}{|l|l|c|}
\hline \multicolumn{1}{|c|}{ Factor } & \multicolumn{1}{|c|}{ Investigation results } & Rate \\
\hline Compatibility & ULCC-Panamax & 4.5 \\
\hline $\begin{array}{l}\text { Master/crew } \\
\text { experience }\end{array}$ & $\begin{array}{l}\text { Master and crew of Panamax class vessel } \\
\text { were involved in 2 lightering operations } \\
\text { over the last year }\end{array}$ & 8.0 \\
\hline $\begin{array}{l}\text { STS Provider } \\
\text { experience }\end{array}$ & $\begin{array}{l}\text { The STS provider has conducted } \\
\text { approximately 500 STS operations over the } \\
\text { last year from which about 250 operations } \\
\text { have been performed from the specific } \\
\text { POAC }\end{array}$ & 3.5 \\
\hline $\begin{array}{l}\text { Environmental } \\
\text { conditions }\end{array}$ & $\begin{array}{l}\text { The wind is about 30-35 knots and the } \\
\text { wave height is 1.0-1.5m }\end{array}$ & 2.8 \\
\hline $\begin{array}{l}\text { Overall risk } \\
\text { estimation }\end{array}$ & $\begin{array}{l}\text { Risk estimation between medium and high } \\
\text { level in the scale 0-10 }\end{array}$ & 7.16 \\
\hline
\end{tabular}

Another indicative example on risk evaluation refers to figure $17 \mathrm{f}$ which shows that although a low level for the experience of the STS provider is translated into a low risk evaluation in case of excellent environmental conditions, however if the weather conditions deteriorate then the relative risk increases. This means that in case of an STS provider with low 
experience the environmental conditions obtain high significant and therefore they should be taken under serious consideration with regards to the decision of giving the green light to the operation.

Another interesting example comes from figures $17 \mathrm{a}$ and $17 \mathrm{e}$ which demonstrate the significant effect of the master's and crew experience to the overall safety of the operation. High level of experience can maintain the risk of the operation in relatively low levels with limited effect by the compatibility of the vessels and the environmental conditions; hence, the master's and crew experience is a factor of special importance. This is also demonstrated from the latest relevant IMO resolution, MEPC 186(59)/2009, which gives to masters of tanker vessels the full operational responsibility of an STS transfer operation ${ }^{4}$.

Figure 18 shows an example from the combination of the input variables yielding the corresponding risk level. In particular, the case of a ULCC lightering operation to a 'Panamax" class vessel is evaluated during the phase of preparation with the objective cause to predict the relative risk of the entire STS operation. The master of the Panamax vessel has evaluated the corresponding factors according to the preliminary investigation. Data interpolation by applying tables 1, 3, 4 and 5 leads to the results shown in Table 7.

The relative risk (potential) can be calculated by moving the black lines depicted in each input variable whereas the results are indicated from the intense black line targeted from the arrow in the risk column in figure 18. The real time adaption of the results of the FIS engine can demonstrate the strength of the proposed model adding dynamic attributes that makes it a valuable tool in hands of experts. The analysis of the results demonstrates that the FIS engine can efficiently be used during the different phases of an STS operation to determine the effects of the factors involved on risk.

Moreover, the FIS model can be applied during the phase of the preparation of the STS operation to evaluate the presenting conditions and estimate the risk of the upcoming operation. The capability of the FIS model is necessary to the decision-making for the conduction or not of the operation after taken into account all possible factors that can affect the STS operation.

\section{Conclusions}

The aim of this paper is to apply FIS as a novel approach on risk assessment for STS transfer operations. From the results it is clear that the selected factors can successfully be combined to map and estimate the risk during such procedures. Hence, the proposed methodology can be used prior to the operation to assess the potential risk of an STS procedure so as to take the necessary measures to mitigate this risk. Moreover, the proposed methodology can be used as a tool during or after the completion of the operation to evaluate the prevailing conditions and thus to provide assistant to the decision-making regarding each one of the different phases of an STS transfer operation.

The STS transfer operations may potentially lead to marine accidents with adverse impact on human life, the environment and property; the risk of a marine accident during an STS operation and subsequently the consequences arising by such an event should be taken under serious consideration. In this context, this paper focused on conducting, in a systematic way, a risk assessment for STS transfer of cargo operations to assist to the study of alleviating and/or mitigating the risk of a potential corresponding marine accident.

\section{Acknowledgments}

This work forms part of the "IKY fellowships of excellence for postgraduate studies in Greece-Siemens program" in which the corresponding author currently participates.

\section{References}

1. National Academy of Sciences (NAS), Committee on Oil Spill Risks from Tank Vessel Lightering,Marine Board, Oil Spill Risks From Tank Vessel Lightering, National Academy Press, (1998), Washington, D.C. Oil.

2. European Commission (EC), 2009. Technical support for European action to reducing GHG emissions, Annex I, Ship-to-Ship transfer. DG ENV.C3/ATA/2008/0016, Delf.

3. BP p.l.c.: "Statistical Review of World Energy", 2012 (online available:http://www.bp.com/statisticalreview)

4. Ventikos N.P., Stavrou I.D, Ship to Ship (STS) Transfer of Cargo: Latest Developments and Operational Risk Assessment, SPOUDAI, Journal of Economics and Business, 2013, Vol.63, Issue 3.

5. Companies International Marine Forum (OCIMF),Ship to Ship transfer guide for petroleum, chemicals and liquefied gases, 2013.

6. International Maritime Organization (IMO), MERC.186 (59), Amendments to the annex of the protocol of 1978 relating to the international convention for the prevention of pollution from ships 1973, (2009).

7. Glykas A, Perissakis S.,A Risk Assessment Methodology as a tool for screening of Ship to Ship (STS) Transfer Operation,European Conference on Shipping,Intermodalism\& Ports (ECONSHIP 2011).

8. DetNorsteVeritas (DNV),Marine Risk Assessment. Offshore Technology Report, (2001), London UK.

9. American Bureau of Shipping, ABS,Guidance notes on risk assessment applications for the marine and offshore oil and gas industries,(2000), Houston (TX). 
10. American Bureau of Shipping,Guide for Risk Evaluations For The Classification Of Marine-Related Facilities, (2003), Houston, USA.

11. Bier V., Anthony L., Probabilistic Risk Analysis for Engineered Systems. Advances: PRA for Eng Systems,(2002).

12. Elsayed $\mathrm{T}$ et al.,Risk assessment of liquefied natural gas carriers using fuzzy TOPSIS,(2013).

13. Mullai A.,A Risk Analysis Framework for Maritime Transport of Packaged Dangerous Goods-A Validating Demonstration,(2007), Lund University.

14. Sii H.S., Ruxton T., Wang J., A fuzzy-logic-based approach to qualitative safety modelling for marine systems, Reliability Engineering and system safety 73(2001) 19-34.

15. MohdJunaizeeMohd Noor, MSc Thesis, Application of knowledge-based fuzzy inference system on high voltage transmission line maintenance, (2004).

16. Othman Z., Subari K., Morad N., Application of fuzzy inference systems and genetic algorithms in integrated process planning and scheduling.

17. Sivarao, Brevern P., El-Tayeb N.S.M., Vengkatesh V.C., GUI based mamdani fuzzy inference system modeling to predict surface roughtness in laser machining, International Journal of electrical \& computer siences, (2009), Vol. 09, No. 09.

18. Rasonlzadeh M., Facial expression recognition using fuzzy inference system, International Journal of Engineering and Innovative Technology,(2012), Vol.1, Issue 4.

19. Kaur A., Chopra V., Fuzzy model for optimizing strategic decision using Matlab, Research cell: An international journal of engineering siences, (Issue Jul 2011), Vol.1.

20. Allahverdi N, Torun S., Saritas I., Design of a fuzzy expert system for determination of coronary heart disease risk, (International conference systems and technologiesCompSys Tech 2007).

21. Saritas I., Allahverdi N., Sert I.U., A fuzzy expert system design for diagnosis of Prostate Canser, (Int. conference systems and technologies-CompSys Tech 2003).

22. Adeli A., Neshat M, A Fuzzy Expert System for Heart Disease Diagnosis,International Multi-conference of engineers and computer scientists,(2010), Vol.1, IMECS, Hong Kong,

23. Tavana M., Azizi F., Behzadian M., A fuzzy inference system with application to player selection and team formation in multi-player sports, Sport Management Review 16, (2013), Pg.97-110.

24. TayK.M., Chen C.J., Lee K.K.,Application of fuzzy inference system (FIS) to criterion-referenced assessment with a case study, Proceedings of the $2^{\text {nd }}$ International Conference of Teaching and Learning, (2009), Malaysia.

25. Moghimi M., Venkatesh J., Zappi P., Rosing T., Contextaware mobile power management using fuzzy inference as a service.

26. Chen Y.T., Mathe J., Fuzzy computing applications for anti-money laundering and Distributed storage system load monitoring.

27. Brcko T., Svetak J., Fuzzy reasoning as a base for collision avoidance decision support system, Education in Traffic and Transport Preliminary Communication,(2013).
28. Elsayed T., Fuzzy inference system for the risk assessment of liquefied natural gas carriers during loading/offloading at terminals,(2009).

29. The MathWorks, Fuzzy logic, Matlab, User's guide,Natick,(2014).

30. Zadeh, L.A, Fuzzy sets, Information and Control, Vol.8, ,(1965), pp. 338-353.

31. Mamdani, E.H. and S. Assilian, "An experiment in linguistic synthesis with a fuzzy logic controller," International Journal of Man-Machine Studies, Vol. 7, (1975), No. 1, pp. 1-13,

32. Skjong R, 2007. Hazid of tanker operations, SAFEDOR project, No IP-516278.

33. Bergmann, Ludwig, Robic, Marine Structural Engineering MMA167, 2012. Assignment 1: Tanker ships, Chalmers University of Technology.

34. Marine Accident Investigation Branch (MAIB), Report on the investigation of the collision between mtSaetta and $\mathrm{mt}$ Conger on completion of a ship to ship transfer 9.5 miles south east of Southwold, UK on 10 August 2009, (Report No $3 / 2010)$.

35. Dynamarine, OSIS STS statistics, Consolidated Report 2011-2013,(Elliniko 2013) Greece.

36. Garibaldi J., John R., Choosing Membership Functions of Linguistic terms.

37. Mandal S., Choudhury J.P., Chaudhuri S.R.B, In Search of Suitable Fuzzy Membership Function of Time Series Data, (International Journal of Computer Science Issues 2012).

38. Zhao J., Bse B., Evaluation of Membership Functions for Fuzzy Logic Controlled Induction Motor Drive, (2002) IEEE.

39. Bai Y., Zhuang H., Wang D., 2006. Advanced Fuzzy Logic Technologies in Industrial Applications, 334p.

40. Bouchon-Meunier B., Dotoli M., Maione B., On the choice of Membership Functions in a Mandani-Type Fuzzy Controller.

41. Elsayed T., 2010, Risk Assessment of Marine LNG Operations, Natural Gas, In Tech.

42. Christensen H, Hensel W, Perez de Lucas A, Sames PC, Skjong R,, Strang T, et al. 2005. SAFEDOR-risk-based ship design, operation and regulation. In: Proceedings of IMAM 05.

43. Loer K., Hamann R.,Skjong R., 2007, HazId of Tanker Operations, SAFEDOR-Design, Operation and Regulation for Safety. 